\title{
EXPERIMENTAL DIAGNOSTIC RESEARCH OF FIXTURE
}

\author{
Vitalii IVANOV, Ivan DEHTIAROV, Yuliia DENYSENKO, Nina MALOVANA, \\ Nataliia MARTYNOVA \\ Sumy State University, 2 Rymskogo-Korsakova St., Sumy, 40007, Ukraine, \\ ivanov@tmvi.sumdu.edu.ua
}

\begin{abstract}
In the article the experimental research of the flexible fixture is shown, which provides sufficient accessibility and allows to perform multiaxis machining of parts, e.g. of levers with one setup. The experimental studies compared with the results of numerical simulation that were previously obtained, confirmed that the proposed fixture design meets all accuracy parameters. The results of experimental studies on the determination of displacements have shown that the values of displacements, determined statically, in the proposed fixtures are smaller than the dedicated ones. The analysis of the data of determination of the frequencies of the proper oscillations in the machining of the levers from steel and cast iron has confirmed that the first critical frequency of the fixture significantly exceeds the similar parameter of dedicated fixture.
\end{abstract}

Keywords: fixture, experimental researches, milling, accuracy, frequency, statistic load, displacement, normal distribution law, $\mathrm{CNC}$ machining

\section{INTRODUCTION}

Fixtures play an important role in ensuring the manufacturing of competitive products. This is confirmed by the fact that they make up $70-80 \%$ of the total amount of tooling, 80-90\% of the cost of production planning is spent on the design and manufacture of fixtures, $10-20 \%$ of the total cost of manufacturing systems is the cost of fixtures, up to $40 \%$ of defective parts arises due to the imperfection of the fixtures [1-4]. Modern manufacturing engineering is characterized by wide nomenclature of the manufactured parts. The increasing in the range of products requires complication of design and development work on the manufacture of technological equipment, especially fixtures. Such production conditions require frequent adjustments to the machining of another batch of parts, which raises the question of the economic feasibility of designing and manufacturing special fixtures for details of a specific size. Therefore, the implementation of flexible fixtures is of great topicality, which provides readjustment to another dimension of parts $[5,6]$.

\section{LITERATURE REVIEW}

Modern tendency of machining is the high intensification of manufacturing processes, that is, the reduction of the cost of machining time by reducing the share of auxiliary time, which, in the conditions of strict competition in the market, the multicomponent details of manufacturing engineering and the capabilities of modern metal- cutting machine tools, is an urgent task nowadays [7].

One of the major solutions to increase the intensity of machining is the development and implementation of flexible fixtures, which have a high level of flexibility and allow machining for a minimum number of setups by increasing tool accessibility and providing multiaxis machining.

The desire to one-setup machining is particularly relevant for the machine tools of the drilling-milling-boring group, because they are machined various parts of the complex spatial configuration with the mutual arrangement of surfaces at different angles with small tolerances of mutual arrangement.

It, generally, requires numerous setups and frequent changeovers to the underlying schemes, which directly affects the accuracy of the finished product.

On the mentioned above machines, generally, prismatic parts, blocks of cylinders, straps, connecting rods, brackets, levers etc. are processed. Also, the milling of the slots on the shafts is performed, drilling of radially located holes in the flanges and disks and holes located at an angle.

Increasing the flexibility and expanding the technological capabilities of the fixtures [8], reducing the preparatory and final time for their adjustment, and, therefore, increasing the efficiency of the use of metal-cutting machine tools is ensured by the development and implementation of adjustable locating modules included in the set of modular adjustable fixtures [9].

However, a significant aspect while designing flexible fixtures is compliance with accuracy indicators. Thus, for instance, Rong and Bai [10] 
did a set of researches on the accuracy of machining. Analyzing of accuracy, the basic surfaces of the workpiece were designed as the middle between the displacements of the clamping elements of fixtures and the displacement of the workpiece. In the analysis of the stability of the position of the fixtures, the authors converted the spatial problem (3D) into a flat problem (2D), and introduced an "operating factor" to consider the effect of frictional force.

Vasundara et al. [11] performed the study of accuracy as the maximum value of the elastic deformation of the workpiece when it was fixed to different fixtures, where the preference was given to the construction, where the deformation is the least with other equal conditions. Chou and others [12] developed a method for determining the points of clamping the workpiece to ensure accuracy during machining. $\mathrm{Wu}$ et al. [13] developed a methodology for monitoring the strength of clamping while providing the required accuracy of machining. They simulated the contacts between the workpiece and the clamping elements of fixture as linear and surface contacts and solved this task using nonlinear programming methods.

Trappey et al. [14] investigated the problem of the temporality of the stability of the position of the fixtures and the effect on the change of the originally achieved accuracy of the situation, considering the limitation of strength and direction of its action in the system "fixture - workpiece".

However, in the above-mentioned studies, it is not shown how flexibility affects the size of the deformation of the elements of the system "fixture workpiece", as well as the absence of research on the "reserve of accuracy" of the fixture. The design solutions for the prismatic parts, the plane and two holes, at the coordinate angle, as well as rotational parts with the datums on the external cylindrical surfaces and internal cylindrical surfaces showed high efficiency in modern machine-building.

However, in the automotive industry, a class of complex parts, which includes levers, brackets, forks, connecting rods, link gears and other parts, is quite widespread.

At present, the machining of such parts is performed using modular fixtures, which either exclude the ability to re-adjust, or allow it to run in a small range of sizes.

For parts of the type of levers a new fixture design has been developed, which allows for the modern equipment to provide multiaxis machining and intensify the manufacturing process of their production [14]. The performed studies of the stress-strain analysis and the modal analysis of the proposed fixture [15] suggest that this fixture can be applied in real production conditions, but it requires an experimental verification of the magnitude of the real displacements of the machined surfaces by the applied forces, as well as the determination of real values of eigenfrequency.

The purpose of this work is to check the possibility of applying the proposed fixture that provides the possibility of re-adjusting the functional elements of the fixture for setups levertype parts in a certain range of dimensions, increases tool availability and allows for multiaxis machining by experimentally checking and comparing the experimental values of displacement values and frequencies of the own eigenfrequency with the simulation results.

\section{RESEARCH METHODOLOGY}

The object of the study is the selection of parts e.g. of levers that are the components of many units of machine-building products, especially in the automotive industry. The subject of the study is the proposed flexible fixture for machining lever-type parts (Fig. 1a). This fixture is intended for the setup of levers of various sizes within the technical specification, and allows to reduce the changeover time and to provide the tool accessibility of machined surfaces [15].

The prototype model with the use of additive technologies from the ABS-plastic (Fig. 1b) was made to check the possibility of assembling and functioning of the fixture. Based on the testing of this model its efficiency was confirmed, and a prototype fixture from metal was made (Fig. 1c). All sizes of fixture elements are obtained because of parametric optimization.

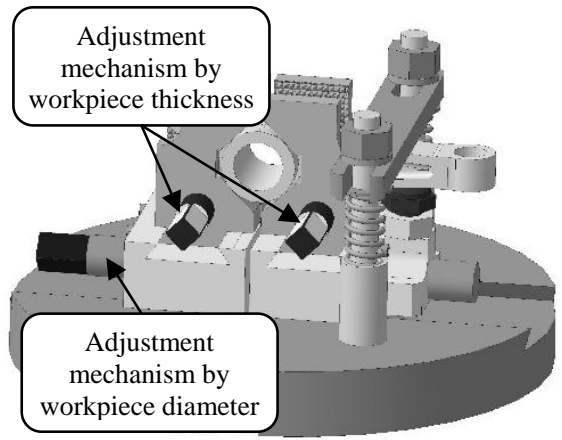

a)

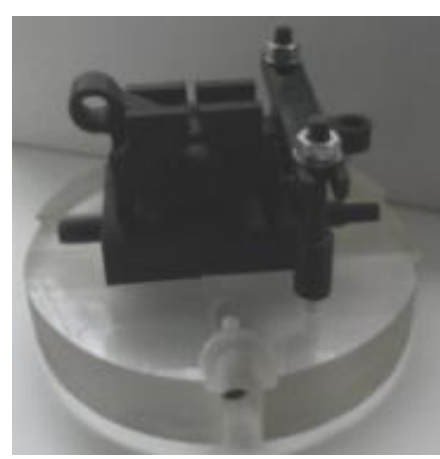

b)

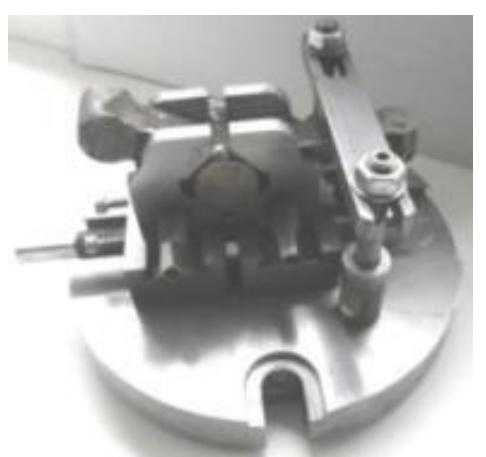

c)

Fig. 1. The proposed fixture: $\mathrm{a}-3 \mathrm{D}$ model; $\mathrm{b}-$ prototype model; $\mathrm{c}-$ experimental model 
Also, for the experimental part of the research, the dedicated fixture (Fig. 2), which consists of plate 1 , mandrel 2 , corresponding to the nominal size of the hole of the central hole of the lever, two supports 3, and a support 4, was developed and manufactured.

To verify the adequacy of the simulation results, experimental research of the stress-strain analysis of the proposed and dedicated fixtures of the manufacturing process were performed. Experimental researches of the stress-strain analysis of fixture provide for the application of loads to the parts of the surfaces to be machined and the value of the displacements at the point of application of

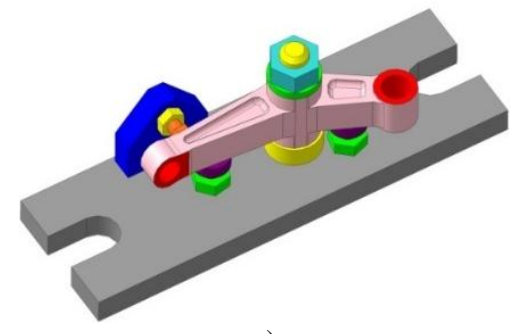

a) the load. To do this, an experimental setup was developed to value the magnitude of the displacements of the machined surfaces under the action of the load (Fig. 3).

According to the measurement schemes for the base part of the experimental stand, a horizontal milling machine and a vertical milling machine were used. At the experimental stand (Fig. 3), the fixing of the fixture 1 on the machine tool table 5 was carried out with the help of fasteners 4 . The forces were applied through the mandrel 6, mounted in the spindle of the machine tool, which operates on the tare dynamometer 3 of the Mohr \& Federhaff model during movement of the table.

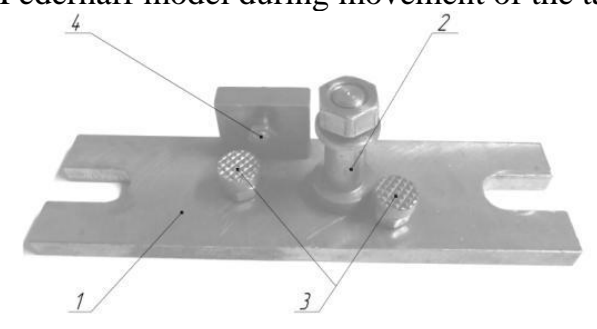

b)

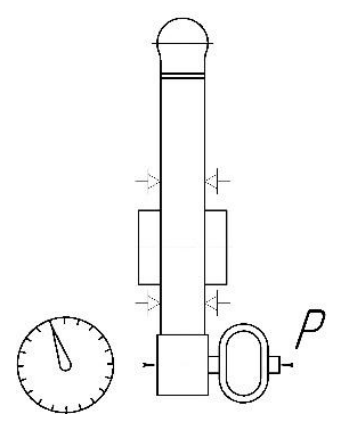

a)

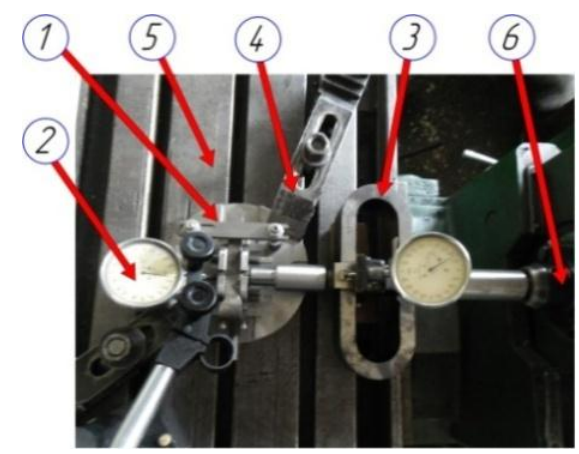

b)

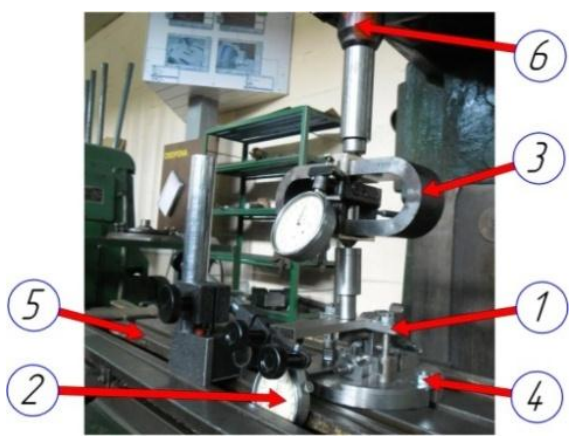

c)

Fig. 3. Stress-strain analysis of the proposed fixture:

$\mathrm{a}$ - principal scheme; $\mathrm{b}$ - in horizontal plane; $\mathrm{c}$ - in vertical plane

The dynamometer is a tare spring clamp, the rigidity of which is known. The magnitude of the force is measured by determining the value of the deformation of the spring clamp, which is fixed by the indicator of the clock type of the model MIG 1 GOST 9696-82. The graduation of the indicator spacing of $0.001 \mathrm{~mm}$ corresponds to a magnitude of $6 \mathrm{~N}$.

To value the displacements of the fixture elements, the estimated values of loads were taken to handle the lever from steel $40 \mathrm{CrNi}$, as the largest that can be encountered during machining. When machining grey cast iron GG20 and aluminum alloy G-AlSi10Mg, the loading that will occur during machining will be significantly less due to the physical and mechanical properties of these materials, therefore, the verification of stressstrain analysis for these conditions was not fulfilled.

The load on the machined surface of the lever in the fixture was performed in a quantity of 30 times on each of the surfaces. At the same time, in the intervals between the loads there was a complete unloading, simulating the process of changeover another workpiece. For the experiment, the grey cast iron GG20 was chosen. The loading process simulating the drilling of the auxiliary holes of the bosses of the lever is accompanied by console loads (Fig. 4).

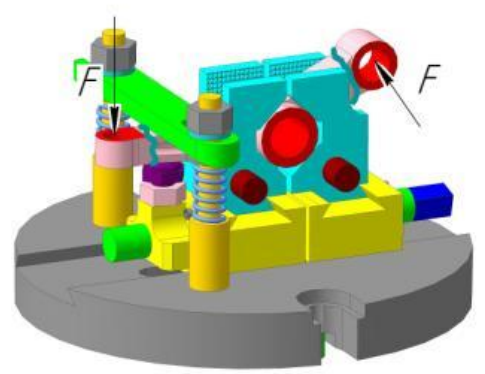

Fig. 4. The loading process simulating the drilling of auxiliary holes of the lever 
This can lead to an excess of the allowable value of the stresses for the cast iron with the application of forces that arise in the machining of steel 40CrNi6. Therefore, the magnitudes of loads for these manufacturing steps are taken as calculations for cast iron.

\section{RESEARCH RESULTS}

The comparison of experimental data and modeling results [16] for the proposed and dedicated fixtures on the most loaded steps is presented in the graphics (Fig. 5-7).

The results of the static stress-strain experiment showed that the values of the displacements of the elements of the fixture are larger by an average of $15 \%$ than the values at similar steps during the simulation, but are still within the permissible limits.

The analysis of histograms (Fig. 5-7) shows that the values of displacements of the elements of the fixture are subject to the normal distribution law. The application of the proposed fixture has a significant effect on the value of the field of dispersion of the accuracy indicators. Thus, when drilling a bodies height of the auxiliary hole parallel to the main, at $\mathrm{F}=3300 \mathrm{~N}$, the dispersion field in the proposed fixture is $17 \mu \mathrm{m}$, and in the dedicated fixture $-28 \mu \mathrm{m}$ (Fig. 6).

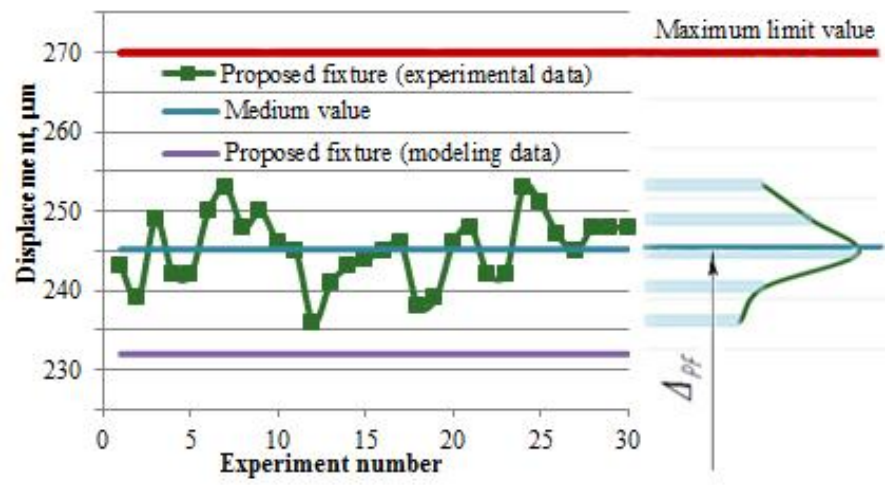

Fig. 5. The comparison of experimental data and modeling data during drilling of main hole in the proposed fixture $(\mathrm{F}=5500 \mathrm{~N})$

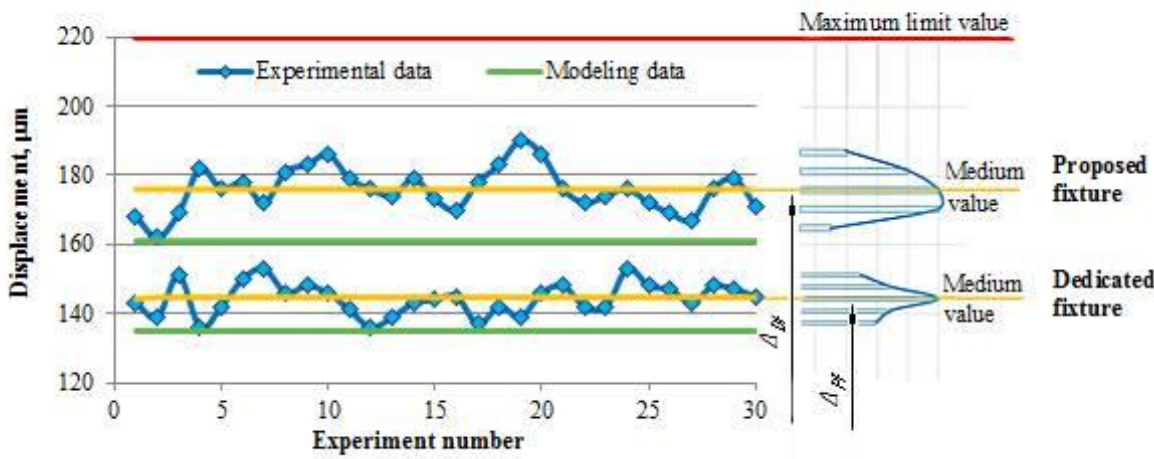

Fig. 6. The comparison of experimental data and modeling data during drilling of auxiliary hole which parallel to the main hole in the proposed and dedicated fixtures $(F=3300 \mathrm{~N})$

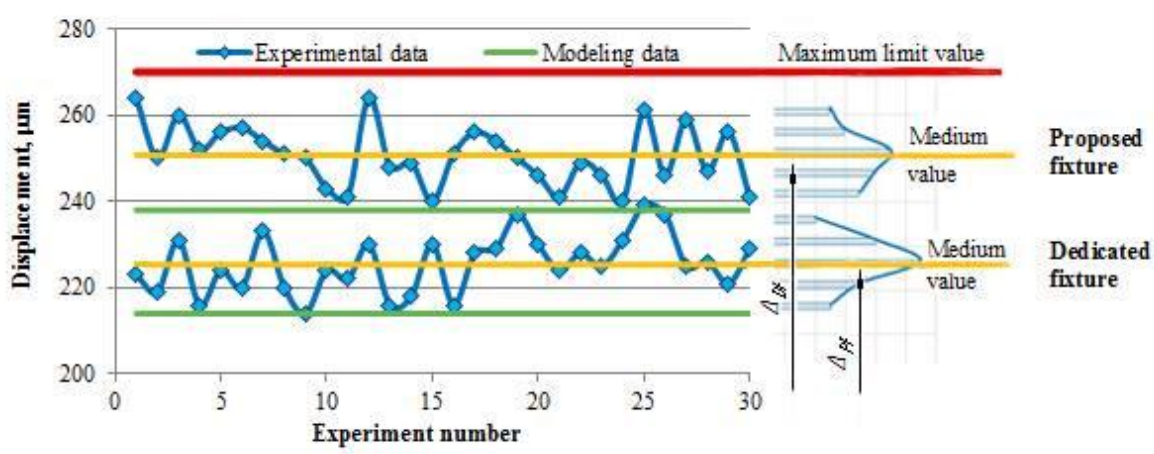

Fig. 7. The comparison of experimental data and modeling data during drilling of auxiliary hole which perpendicular to the main hole in the proposed and dedicated fixtures $(\mathrm{F}=2400 \mathrm{~N})$ 
When machining the auxiliary hole perpendicular to the main one, at $\mathrm{F}=2400 \mathrm{~N}$, the dispersion field in the proposed fixture is $25 \mu \mathrm{m}$, and in the dedicated fixture $-24 \mu \mathrm{m}$ (Fig. 7).

The width of the distribution of histograms is much smaller than the width of the tolerance, so the probability of occurrence of defective products due to the error of clamping the workpiece is minimal. The location of histograms is shifted relative to the middle of the tolerance in the direction of the upper limit, but the probability of occurrence of defective products when applying the proposed fixture is lower than when applying a dedicated fixture. In addition, the analysis of the location of the dispersion fields indicates that the margin of accuracy of the proposed fixture is much greater than that of the dedicated fixture.

This can be explained by a lower value of the error of the configuration $\triangle P f$ of the proposed fixture. In the foreseeable future, the research is proposed to minimize this parameter.

The discrepancy between the results can be explained by the errors in the value of the forces and displacements, as well as the actual properties of the material of the parts of the fixture, which may differ from the reference books within the permissible limits. In this case, a similar situation is observed for a dedicated fixture. It is worth noting that the error of the magnitude of displacement increases with an increase in the load on the elements both in the proposed fixture, and in the dedicated fixture. Consequently, proceeding from the foregoing it can be argued that the boundary conditions were given correctly.

It is known, processes of machining are often accompanied by oscillations, so it is important to identify and prevent their possible occurrence. This can be done if you know the frequency of your own system fluctuations. Each system has an infinite number of eigenfrequencies and their forms (mods), but as a rule, in most cases, the first three frequencies must be known for the fixture. Variation forms may or may not have periodicity, but each non-periodic form can be expanded to a multitude of periodic ones. Fluctuations are characterized by frequency and period, but from the point of view of ensuring the design efficiency and preventing resonance occurrence it is necessary to know exactly the frequency of the internal oscillations of the investigated structure.

Experimental modal analysis of the fixture for a progressive and typical manufacturing processes was performed according to the setup scheme (Fig. 8).

For the experimental determination of eigenfrequencies, the equipment of the National Instruments company was used. Both sets contain the fixture (proposed or dedicated) 1, which is mounted on the machine tool table 2 and is fastened with nuts 3 , as well as a device for registering the eigenfrequencies 4 with the help of sensors 5 . The fixtures were firmly fixed on the machine tool table to avoid side-effects that could be fixed by the sensors and make an error in the experiment. The massive construction of the machine bed will extinguish possible external oscillations. A special hammer 6 with a rubber tip is used to excite oscillations in the system "fixture - workpiece". The initial impulse was provided by hammering the console elements of the system "fixture workpiece" (bodies of the main and auxiliary holes).

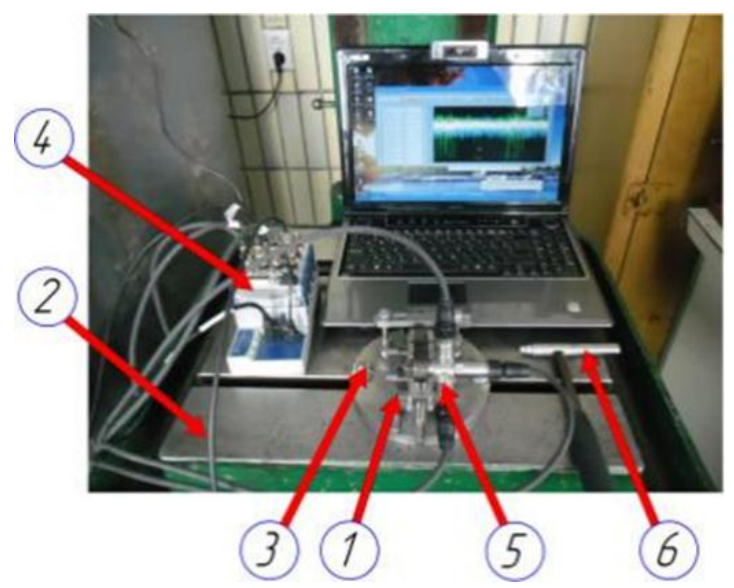

Fig. 8. Experimental setup for modal analysis

As a result of experiments, the instantaneous values of the vibration accelerations fixed by the sensors are obtained at definite intervals $(0.001$ $\mathrm{sec})$. Therefore, in order to determine the experimental frequencies of fixture eigenfrequencies, it is necessary to determine the spectra of the eigenfrequencies, which can be carried out by means of the decomposition of the experimental values of the vibration acceleration in the vibrational displacement. This procedure is possible by dual integration of the vibration acceleration function in the vibration of the displacement using the "fast Fourier transform" method. Thus, by performing a dual integration with the MathCAD software, we obtain the spectra of the eigenfrequencies, which are presented in graphic form (Fig. 9), where the peaks correspond to critical frequencies.

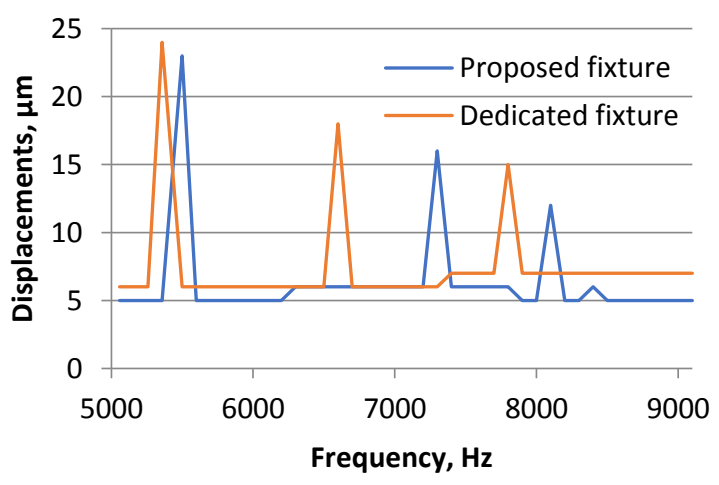

Fig. 9. The spectra of the eigenfrequencies 
Analyzing the graphics, we can conclude that the eigenfrequencies for the proposed fixture are higher than for the dedicated fixture, and therefore the stiffness of the proposed fixture is expected to be higher. The phenomenon of resonance in the machining of the lever in both designs does not arise, since the maximum frequency of the cutting process does not reach the first eigenfrequency fixture. As a result of experiments, the first critical values of the frequencies of the own oscillations were determined: the proposed fixture $-5516 \mathrm{~Hz}$; the dedicated fixture $-5417 \mathrm{~Hz}$. The comparison of theoretical and experimental studies of the eigenfrequencies of the fixtures is given in Table 1 .

Comparing the results (Table 1) it is defined that the value of the eigenfrequencies of the oscillations obtained experimentally is less than in the simulation by $8 \%$, which, when compared with the results of stress-strain analysis, is logical in connection with the real production conditions and inaccuracies in the manufacture of the fixture.

Although the actual displacement values are larger and the values of the eigenfrequencies are lower than during the simulation, they still do not exceed the machining tolerances and the resonance frequencies correspondingly, therefore, it is possible to guarantee the receipt of the machined parts within the tolerances according to the drawing.

Table 1. The comparison of theoretical and experimental studies of the eigenfrequencies of the fixtures

\begin{tabular}{|l|c|c|c|c|c|c|c|c|c|}
\hline \multirow{2}{*}{ Fixture } & \multicolumn{3}{|c|}{$\begin{array}{c}\text { Critical frequency, Hz } \\
\text { (modeling data) }\end{array}$} & \multicolumn{3}{c|}{$\begin{array}{c}\text { Critical frequency, Hz } \\
\text { (experimental data) }\end{array}$} & \multicolumn{3}{c|}{ Error, $\%$} \\
\cline { 2 - 11 } & 1 & 2 & 3 & 1 & 2 & 3 & 1 & 2 & 3 \\
\hline $\begin{array}{c}\text { Dedicated } \\
\text { fixture }\end{array}$ & 5888 & 7268 & 8250 & 5417 & 6578 & 7766 & 9 & 9,5 & 5,9 \\
\hline $\begin{array}{c}\text { Proposed } \\
\text { fixture }\end{array}$ & 5970 & 7830 & 8915 & 5516 & 7290 & 8250 & 7,6 & 6,9 & 9,2 \\
\hline
\end{tabular}

\section{CONCLUSIONS}

- It is proved that the technical solutions developed contribute to the intensification of machining and do not lead to deterioration of accuracy. The conducted experimental researches of the stressstrain analysis have shown that the developed design of the fixture for the machining of levers provides multiaxis machining and meets the conditions of strength, as well as significantly reduces the costs of the auxiliary and preparatory time.

- Experimental researches of the stress-strain analysis of the system "fixture - workpiece" system, which showed that the values of displacements of the elements of the fixture are larger by an average of $15 \%$ than the value of the values at similar transitions during the simulation. However, the values of real displacements also do not exceed the value of the tolerances given in the drawing.

- Experimental studies of the frequencies of the own fluctuations of the system "fixture workpiece" showed a decrease in the frequencies of their own real designs of the proposed and dedicated fixture by $8 \%$ compared to the results of simulation. The actual frequencies of their own oscillations exceed the machining modes, so there is no resonance.

- Subsequent studies are aimed at an experimental verification of the possibility of machining the lever with given precise parameters directly on the machine, as well as the development of a fixture for machining other complex parts using a new approach to fixture design.

\section{REFERENCES}

1. Hashemi H, Shaharoum AM, Sudin I. A case-based reasoning for design of machining fixture. International Journal of Advanced Manufacturing Technology 2014; 74: 113-124. https://doi.org/10.1007/s00170-014-5930-4

2. Wang H, Rong Y, Li H, Shaun P. Computer aided fixture design: recent research and trends. ComputerAided Design, 2010; 42 (12): 1085-1094. https://doi.org/10.1016/j.cad.2010.07.003

3. Bi ZM, Zhang WJ. Flexible fixture design and automation: review, issues and future directions. International Journal of Production Research, 2001; 39: 2867-2894. https://doi.org/10.1080/00207540110054579

4. Erdem I, Levandowski C, Berlin C, Kihlman H, Stahre J. A novel comparative design procedure for reconfigurable assembly fixtures. CIRP Journal of Manufacturing Science and Technology, 2017; 19: 93-105. https://doi.org/10.1016/j.cirpj.2017.06.004

5. Gothwal S, Raj T. Different aspects in design and development of flexible fixtures: review and future directions. International Journal of Services and Operations Management, 2017; 26(3): 386-410. https://doi.org/10.1504/IJSOM.2017.081944

6. Gameros A, Lowth S, Axinte D et al. State-of-the-art in fixture systems for the manufacture and assembly of rigid components: A review. International Journal of Machine Tools and Manufacture, 2017; 123: 1-21. https://doi.org/10.1016/j.ijmachtools.2017.07.004

7. Karpus V, Ivanov V, Kotliar O et al.: Intensification of manufacturing processes. Sumy State University, Sumy, 2012. (in Ukrainian). https://doi.org/10.13140/2.1.3953.7604

8. Ivanov V, Dehtiarov I, Pavlenko I. Mathematical model of the fixture flexibility impact on machining accuracy of levers. Acta Mechanica Slovaca, 2016; 20(2): 6-15. 
9. Karpus' VE, Ivanov VA. Universal-composite adjustable machine-tool attachments. Russian Engineering Research, 2008; 28(11): 1077-1083. https://doi.org/10.3103/S1068798X08110105.

10. Rong Y, Bai Y. Automated generation of modular fixture configuration design. Journal of Manufacturing Science and Engineering, 1997; 119(2): 208-219. https://doi.org/10.1115/1.2831097

11. Vasundara M, Padmahaban KP, Sabareeswaran M, RajGanesh N. Machining faxture layout design for milling operation using FEA, ANN and RSM. Procedia Engineering 2012; 38: 1693-1703. https://doi.org/10.1016/j.proeng.2012.06.206

12. Chou YC. Automated fixture design for concurrent manufacturing planning. Concurrent Engineering: Res. \& Appl. 1993; 1: 219-229.

https://doi.org/10.1177/1063293X9300100405

13. Wu Y, Rong Y, Chu T. Automated generation of dedicated fixture configuration. International Journal of Computer Applications in Technology 1997; 10(3/4): 213-235.

https://doi.org/10.1504/IJCAT.1997.062249

14. Trappey AJC, Su CS, Hou JL. Computer-aided fixture analysis using finite element analysis and mathematical optimization modeling. ASME INECE, MED 1995; 2(1): 777-787.

15. Ivanov VO, Dehtiarov IM, Karpus VE. Patent of Ukraine № 98925. Adjustable locating-and-clamping module for machining of levers, 2015.

16. Ivanov V, Mital D, Karpus V et. al. Numerical simulation of the system "fixture - workpiece" for levers machining. International Journal of Advanced Manufacturing Technology, 2017; 91(1-4): 79-90. https://doi.org/10.1007/s00170-016-9701-2

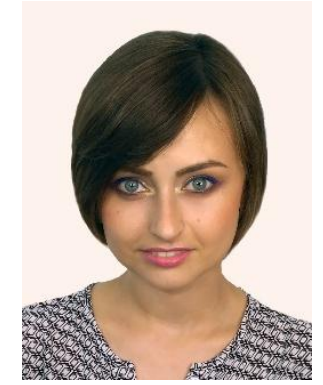

Yuliia DENYSENKO

Ph.D., Senior Lecturer, Department of Manufacturing Engineering, Machines and Tools, Sumy State University. Her scientific interests concern among manufacturing engineering, quality management and standardization.

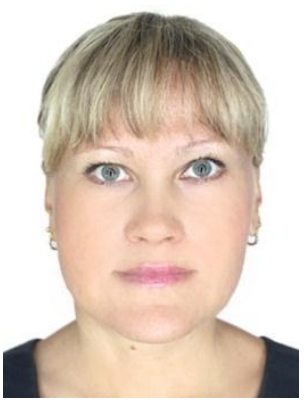

Nina MALOVANA, Ph.D., Senior Lecturer, Department of Foreign Languages, Sumy State University. Her scientific interests are related to the subject of verbal and non-verbal communication, professional engineering terminology.

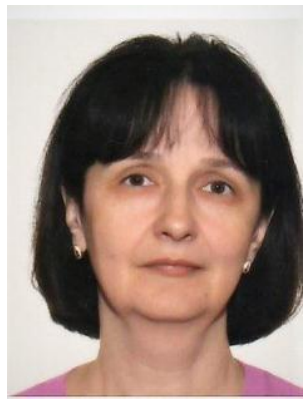

Nataliia MARTYNOVA,

Ph.D., Associate Professor, Department of Mathematical Analysis and Optimization Methods, Sumy State University. Her scientific interests are related to the subject of mathematical modelling and prediction of characteristics of technical systems in engineering.

Received 2018-02-19

Accepted 2018-05-22

Available online 2018-07-03

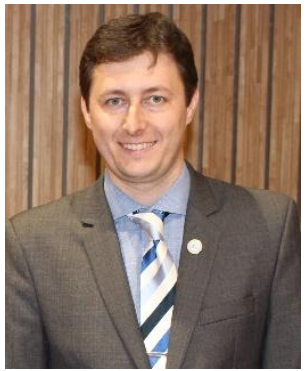

Vitalii IVANOV,

Ph.D., ING. PAED. IGIP, Associate Professor, Department of Manufacturing Engineering, Machines and Tools, Sumy State University. His scientific interests are related to $\mathrm{CAx}$ technologies for manufacturing engineering, product design and intensification of manufacturing processes, and fixture design: analysis, optimization, verification.

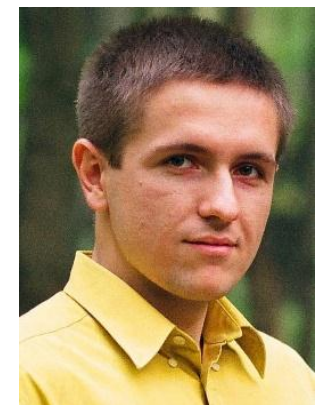

\section{Ivan DEHTIAROV}

Ph.D., Assistant Professor, Department of Manufacturing Engineering, Machines and Tools, Sumy State University.

His scientific interests are related to the subject of fixture design and verification, cutting processes, CNC machining. 